\title{
A Preliminary Study on the Safety, Efficacy and Acceptability of the Community Preparation of Siling Labuyo (Capsicum frutescens) Liniment in the Management of Knee Osteoarthritis in a Six-Week, Active-Controlled Community-Based Clinical Trial
}

\author{
Elizabeth R. Paterno, ${ }^{1}$ Clarisse A. Pangilinan, ${ }^{2}$ Erna C. Arollado ${ }^{2}$ and Rachael Marie B. Rosario ${ }^{1}$ \\ ${ }^{1}$ Department of Family and Community Medicine, College of Medicine and Philippine General Hospital, University of the Philippines Manila \\ ${ }^{2}$ Institute of Pharmaceutical Sciences, National Institutes of Health, University of the Philippines Manila
}

\begin{abstract}
Objective. The study determined the safety, efficacy and acceptability of a Philippine community preparation of Siling Labuyo liniment in the management of knee osteoarthritis.

Methods. A 6-week randomized, double-blind, active-controlled clinical trial was conducted in three municipalities of Cavite from 2017-2018. The municipalities were randomly assigned to either the control or experimental group, using a commercially available Diclofenac $1 \%$ gel as the control agent. Knee Injury and Osteoarthritis Outcome Score (KOOS) and Pain Visual Analogue Scale (VAS) were used to measure the outcomes.
\end{abstract}

Results. Forty-seven participants completed the study. Statistically significant improvement $(p<0.05)$ in pain relief, reduction of symptoms and increase in knee functionality was reported by participants in both the experimental and control groups. Across the dimensions measured, at least $30 \%$ improvement in scores was reported by the experimental group, and at least $40 \%$ by the control group. The difference was statistically not significant $(p>0.05)$. Itching (13\%), burning sensation (11\%) and reddening of the skin (15\%) were experienced in both the experimental and the active control groups.

Conclusion. Use of the liniment led to a modest therapeutic effect and was well-tolerated by the participants.

Key Words: Capsicum frutescens, Diclofenac, knee osteoarthritis, pain

\section{INTRODUCTION}

Paper was presented at the NIH Research Forum, September 17, 2018, NIH Centennial Conference Room, National Institutes of Health, University of the Philippines Manila.

Corresponding author: Elizabeth R. Paterno, MD, MPH Department of Family and Community Medicine Philippine General Hospital University of the Philippines Manila

Taft Avenue, Manila 1000, Philippines

Email: bebolrp@gmail.com
Osteoarthritis (OA), also known as degenerative arthritis, is a disease characterized by loss of joint cartilage and narrowing of joint spaces. Factors such as age, obesity and frequent joint use had been associated to the progression of the disease. ${ }^{1,2}$ In Asia, the most common type of OA is knee osteoarthritis. ${ }^{2}$ Current developments in managing OA primarily target pain reduction and increased functionality of the affected joint since no cure is available. ${ }^{3}$ Pharmacological treatment, in comparison to non-pharmacological and surgical interventions, is the most common management option used in OA despite knowledge and patient's perception of more effective interventions. ${ }^{4-6}$

Among the available pharmacological agents used in $\mathrm{OA}$, topical non-steroidal anti-inflammatory drugs 
(NSAIDs) is a popular management option among older Asian populations not only because topical drugs cause less risk of resulting to a systemic event like renal, cardiovascular and gastro-intestinal (GI) adverse effects compared to the oral preparations. ${ }^{7,8}$ Nevertheless, even topical NSAIDS showed the possibility of GI and cardiovascular-linked adverse effects. ${ }^{9,10}$ As such, plant-derived products are currently being explored due to their minimal likelihood of systemic absorption compared to topical NSAIDs. ${ }^{11,12}$

In the Philippines, one of the plants with documented folkloric use in the management of rayuma (this could be equivalent to osteoarthritis) is siling labuyo. ${ }^{13-15}$ (Figure 1) This plant produces capsaicinoids, which are compounds with potential analgesic effect. This plant-derived metabolite is characterized by a benzene structure that accounts for its pungency and the modifications of side-chains determine its potency and activity. ${ }^{16,17}$ Capsaicin, the parent metabolite, induces noxious effects followed by the analgesic effect. This nonpolar transient receptor potential vanilloid 1 (TRPV1) agonist allows influx of calcium ions that produces action potentials and subsequently activates cascades correlated to signals like burning or stinging sensation reported in topical capsaicin use. ${ }^{16}$ Decrease in signals related to inflammation had been correlated to its analgesic effect. ${ }^{18}$ Continuous application or high doses of capsaicin could also disrupt mitochondrial respiration in nerves leading to 'defunctionalized' nociceptors. ${ }^{19}$ Consistent with this was the observed loss of epidermal nerve fibers after continuous application of capsaicin. ${ }^{20}$ In several clinical trials, topical capsaicin provided significant analgesic effect compared to placebo and control at concentrations ranging from 0.075 to $0.0125 \%{ }^{12,21,22}$ In these studies, burning sensation at the application site was primarily reported but this was significantly reduced in terms of intensity and duration after repeated exposure to topical capsaicin. ${ }^{23}$

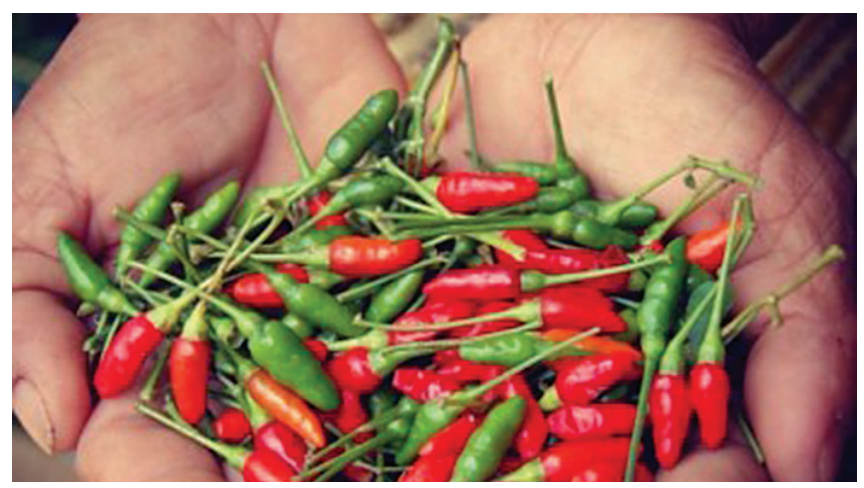

Figure 1. Philippine Siling Labuyo (Capsicum frutescens).

In many rural areas of the Philippines, the Siling Labuyo liniment has been used for a long time to alleviate pain and inflammation in osteoarthritis. ${ }^{14}$ It provides an alternative for commercial OA drugs which are often either unavailable in these areas or too expensive for those needing them.
The siling labuyo plant is grown in almost all regions of the country and the liniment is easy to prepare. ${ }^{14}$ This study was conducted to determine the safety, efficacy and acceptability of the community preparation of the Siling Labuyo liniment to provide evidence for the promotion of its use not only in rural areas and indigent communities, but also among elderly people suffering from OA who are looking for safe alternatives to NSAIDs.

\section{MATERIALS AND METHODS}

\section{Study design}

This is a randomized, active-controlled study conducted in Alfonso, Amadeo and Mendez municipalities of Cavite, Philippines between June 2017 and March 2018. The University of the Philippines Manila Research Ethics Board (UPMREB) approved the study protocol (UPMREB 2016289-01). After a detailed explanation about the nature of the study, all participants signed a written informed consent prior to the trial.

\section{Recruitment and screening}

The sample size computed for the research was 126 participants. Participants of either sex, aged 40 years and above with clinically diagnosed knee OA, supported by classical radiological findings in one or both the knees were recruited in the study. ${ }^{24}$ Exclusion criteria included lactating and pregnant women; patients with severe disabling arthritis and/or incapacitated and bedridden; patients taking antipyretic, analgesics, tranquilizers, hypnotics, excessive alcohol or any other drug which would interfere with pain perception; patients needing drug therapy for OA; and, any patient considered not eligible according to the investigator's discretion. ${ }^{24}$ Participants on NSAIDs were requested to discontinue medication at least a week prior to the start of the trial period. ${ }^{25}$

\section{Liniment preparation}

Siling labuyo fruits were collected in Barangay Lutucan, Sariaya, Quezon, Philippines from early to mid-May 2017. A voucher specimen was submitted to the National Museum for authentication. Garbling was performed and the fruits were washed to remove dirt and clinging insect debris. The fruits were prepared in the method used in rural areas of the Philippines as documented by Co with some modifications. ${ }^{14}$ The control agent used was Diclofenac gel (Voltaren Emulgel $1 \%$, supplied by Glaxo-Kline Smith). Both the control and experimental agents were placed in opaque coded containers and stored at room temperature prior to distribution.

\section{Treatment Allocation and Concealment}

Patient screening and assessment were done in three municipal health centers. Two municipalities were randomly assigned to the use of the Diclofenac gel while one municipality was assigned to the Siling Labuyo liniment. 
This was done to minimize disclosure of the drug among participants within the same municipality since the control was very different from the experimental agent in terms of physical properties. Only the research assistant was aware of which treatment was given to the participating subjects. Both the physicians who assessed the patients and the patients themselves were blinded to the patient's treatment.

\section{Participant Instructions and Clinical Evaluation}

The trial ran for 6 weeks and participants were seen thrice: at baseline and at the end of weeks 3 and 6. Demographics and baseline data were collected on the first visit. Participants who met the criteria were instructed to apply approximately $1 \mathrm{~g}$ (or 3 scoops; using identical scoops provided to measure the medication) of the assigned medication three times daily on the affected knee. Participants with bilateral OA were instructed to apply the drug on the more symptomatic knee. Treatment compliance was estimated by weighing returned containers of the study medications. Each participant was given a pack of 10 tablets of Paracetamol (500 mg), and up to $1 \mathrm{~g}$ per episode was allowed to be taken as rescue analgesic should participants feel pain attributable to the experimental or control agent during the treatment period. If $1 \mathrm{~g}$ of Paracetamol was insufficient to control the pain, participants were instructed to contact the researchers or the Municipal Health Officers for further instructions. Participants were also instructed on how to store, carry and handle the liniment or gel containers to minimize spillage.

Adverse reactions to the treatment was determined by the occurrence of any or any combination of seven local symptoms (itching, burning sensation, reddening of the skin, urticaria, papules, blisters and others) and was evaluated on a 4 -point scale $(0=$ none, $1=$ mild, $2=$ moderate, $3=$ severe/ intense). Participants were also asked about the occurrence of any other adverse events at the second and third visits. Efficacy of medication was assessed using the Knee Injury and Osteoarthritis Outcome Score (KOOS) Filipino version LK 1.0 and Pain Visual Analogue Scale (VAS) scores during the three visits. ${ }^{26-28}$ The KOOS is a tool used in OA treatment assessment that measures five outcome dimensions: pain (Pain), other symptoms (Sym), function in activities of daily living (ADL), function in recreation and sports (Sport/Rec), and knee-related quality of life (QOL). ${ }^{26}$ The Filipino version was validated in a study conducted by Misa and Penserga in the Philippine General Hospital and published online. ${ }^{28}$ The Pain Visual Analogue Scale (VAS) is a horizontal 100-mm line with the 0 end labeled as 'no pain' and the $10-\mathrm{cm}$ end as 'very severe pain.' The score is determined by measuring the distance of the mark that patients are asked to make in the horizontal line from the 'no pain' end. ${ }^{29}$ The VAS was first introduced in 1920 and has been used extensively worldwide. It is included in research evaluation instruments like the Western Ontario and McMaster Universities Osteoarthritis Index (WOMAC), which is regarded as the gold standard in the evaluation of osteoarthritis treatment research. ${ }^{30}$
Decreases in the Pain VAS scores across the treatment period signify improvement or diminishing pain, while in the KOOS, improvement in function and diminishing pain are signified by increases in the scores.

On the third visit, participants were asked to record the onset of treatment effect and to indicate the acceptability of the treatment by noting whether they would continue to use the assigned medication given the chance. ${ }^{31}$

\section{Statistics}

Variables were expressed using mean, standard deviation and/or standard error of measurement unless indicated otherwise. Baseline demographics, baseline KOOS and VAS scores, and knee OA duration were compared using Independent Samples t-test. Data from the 5 outcome measurements of the KOOS and Pain VAS Scores were analyzed using ANOVA of Repeated Measures to determine differences in each visit compared to the baseline within the groups. Groups were compared using Two-way ANOVA of Repeated Measures. Significant difference was set at $\mathrm{p}<0.05$. Statistical analysis was performed using Stata 14 and SPSS ver. 23.

\section{RESULTS}

\section{Participants}

Fifty-six community residents with OA from the 3 municipalities volunteered to participate in the study. Out of the 56 potential participants, 4 were considered ineligible. During the 6-week trial, 5 participants withdrew from the study due to personal reasons. At the end of the study period, data gathered from 47 participants who completed the study were analyzed (Figure 2).

Baseline demographics, baseline KOOS and VAS scores, and knee OA duration were comparable between the two groups $(p>0.05)$ when Independent Samples t-test was performed on the data. Mean age and body mass index (BMI) between groups were likewise comparable (2-tailed $p>0.05)$. The demographics of the two treatment groups are summarized and compared in Table 1.

\section{Efficacy}

Mean KOOS and Pain VAS scores at baseline and at week 6 are shown in Table 2 and Figure 3. Within each treatment group, statistically significant improvement both in the 5 dimensions measured by the KOOS and the Pain VAS Scores was reported by the participants when compared to baseline at the end of the 6-week treatment period. Increases in the KOOS scores tended to be higher in the active control group compared to the experimental group but the differences in the scores between the 2 groups were not found to be statistically significant $(p>0.05)$. Similarly, decrease in the Pain VAS Score was greater in the control group (65\%) compared to the experimental group (46\%), but again the difference was not shown to be statistically 


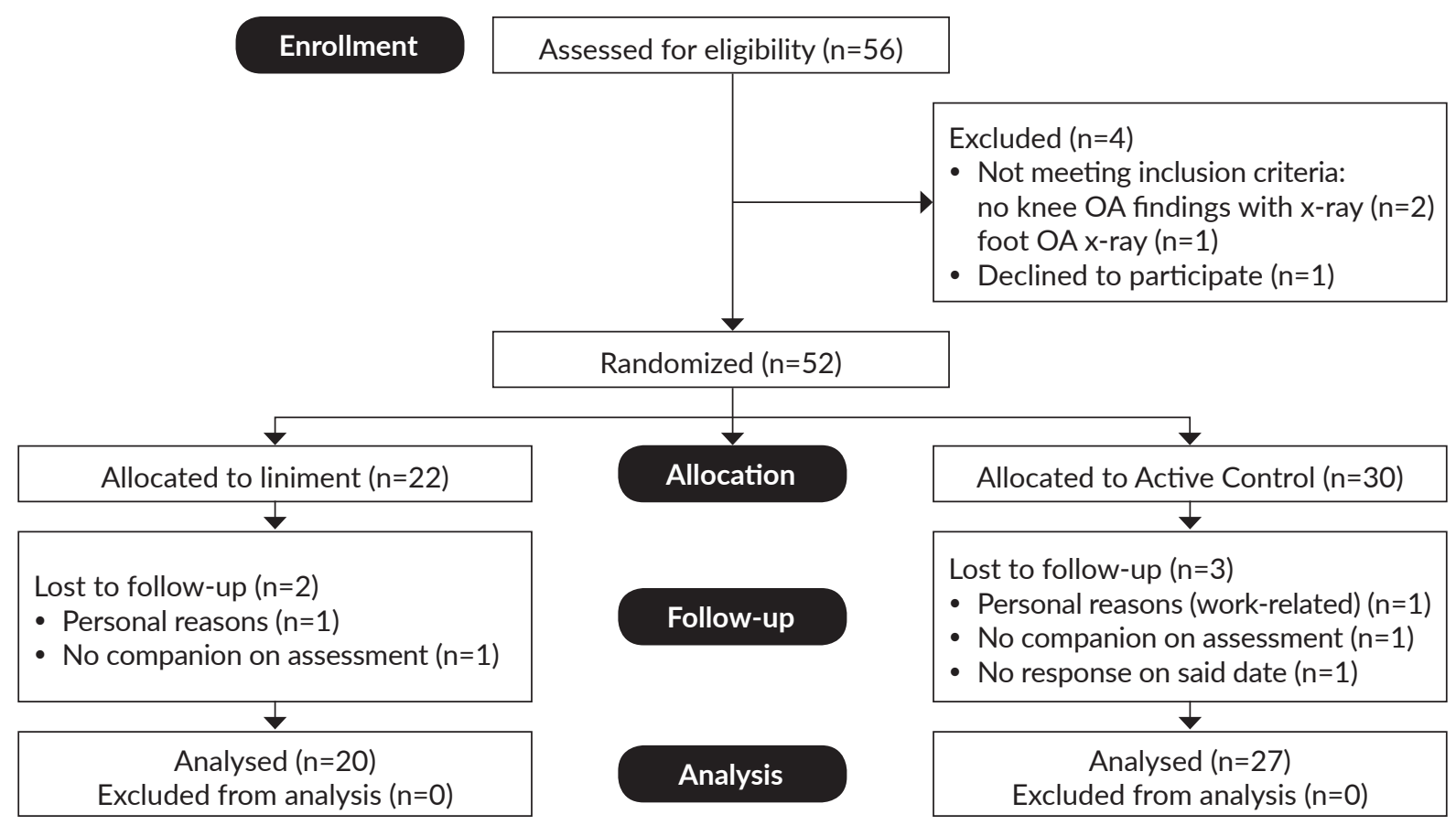

Figure 2. Study flow diagram.

Table 1. Socio-demographics and clinical characteristics of participants

\begin{tabular}{|c|c|c|}
\hline Characteristics & Siling Labuyo ( $N=20$ ) & Control Group ( $\mathrm{N}=27$ ) \\
\hline Male:Female & 3:17 & $6: 21$ \\
\hline \multicolumn{3}{|l|}{ Marital Status } \\
\hline Single & - & 1 \\
\hline Married & 11 & 10 \\
\hline Separated & - & 2 \\
\hline Widowed & 9 & 14 \\
\hline \multicolumn{3}{|l|}{ Educational Background } \\
\hline Primary & 9 & 12 \\
\hline Secondary & 5 & 9 \\
\hline Tertiary & 5 & 6 \\
\hline Age $^{\text {a, }}$ (year) & $70.5 \pm 9.0$ & $70.0 \pm 10.0$ \\
\hline Weight ${ }^{a}(\mathrm{~kg})$ & $60.01 \pm 11.93$ & $65.20 \pm 11.50$ \\
\hline Height ${ }^{a}(\mathrm{~m})$ & $1.52 \pm 0.05$ & $1.53 \pm 0.09$ \\
\hline $\mathrm{BMI}{ }^{\mathrm{a}}\left(\mathrm{kg} / \mathrm{m}^{2}\right)$ & $25.94 \pm 4.59$ & $27.62 \pm 3.66$ \\
\hline \multicolumn{3}{|l|}{ OA Knee ${ }^{b}$} \\
\hline Left & 5 & 14 \\
\hline Right & 15 & 13 \\
\hline Use of Assistive Devices ' (e.g. canes, crutches, etc.) & $6(30.0 \%)$ & $11(40.7 \%)$ \\
\hline OA Etiology, Primary vs. Secondary & 20 vs. 0 & 25 vs. 2 \\
\hline Duration ${ }^{\mathrm{a}}$ (years) & $5.3 \pm 5.9$ & $4.1 \pm 3.4$ \\
\hline \multicolumn{3}{|l|}{ Drugs for OA Management } \\
\hline NSAIDs (celecoxib, etc.) & 18 & 16 \\
\hline Supplements (glucosamine, chondroitin, etc.) & 10 & 4 \\
\hline Topical (yellow ginger, catingco, warm compress, etc.) & - & 4 \\
\hline Injections & 8 & 9 \\
\hline Comorbidities & - & 1 \\
\hline Diabetes (Type 2) & 5 & 6 \\
\hline Hypertension & 8 & 11 \\
\hline
\end{tabular}

Baseline demographics, baseline KOOS and VAS scores, and knee OA duration $p>0.05$ on independent samples $t$-test.

Mean age and body mass index (BMI) $p>0.05$ on 2-tailed t-test. 

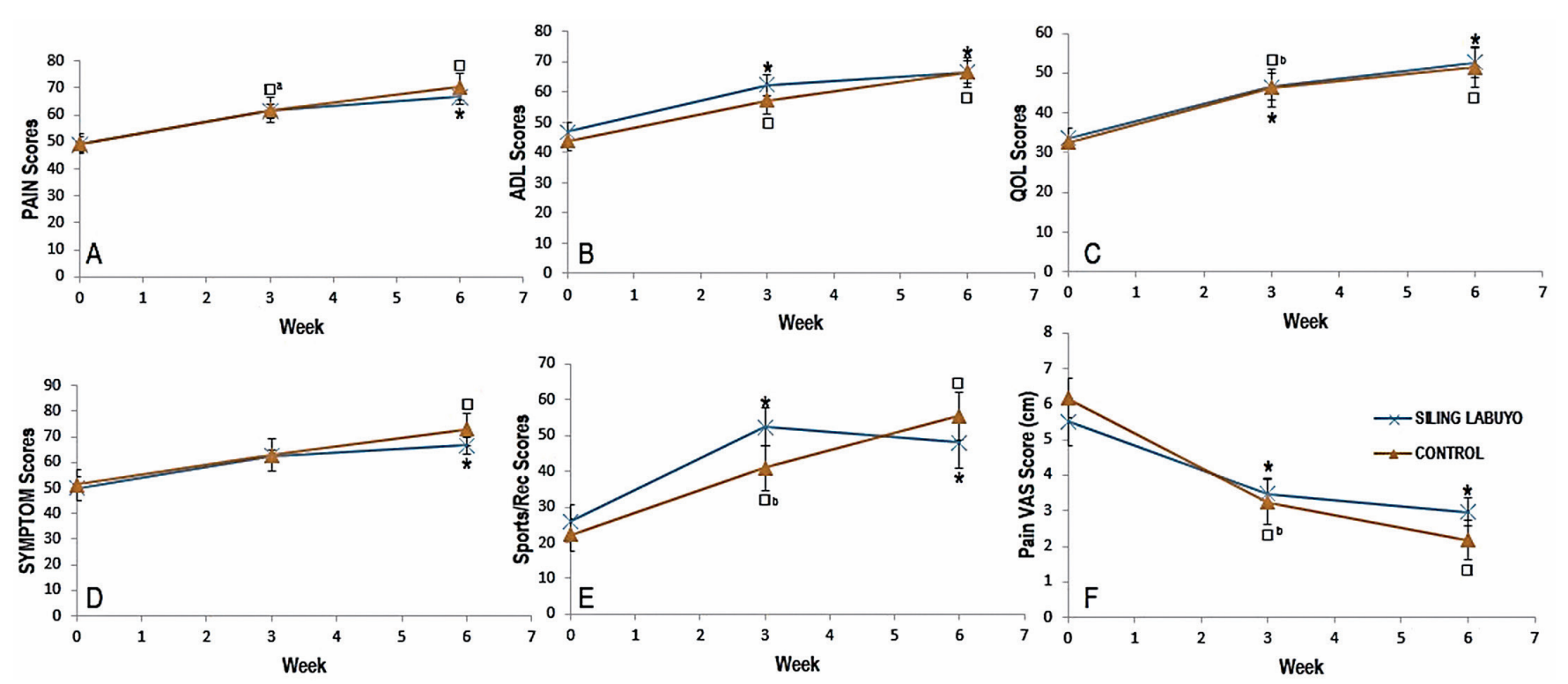

Figure 3. Mean scores and standard error are presented for (A) KOOS Subscale Pain scores (B) KOOS ADL scores (C) KOOS QOL scores (D) KOOS Subscale Symptom scores (E) KOOS Subscale Sports/Rec scores and (F) Pain VAS scores for siling labuyo $(x)$ group and control group $(\boldsymbol{\Lambda})$. Significant changes $(\mathrm{p}<0.05)$ from baseline to week 3 and week 6 within the siling labuyo group are noted with an asterisk $(*)$. Significant changes $(p<0.05)$ from baseline to week 3 and week 16 within the control group are noted with a square ().

a 1 Missing entry on week 3 ; $^{b} 3$ Missing entries on week 3.

KOOS Knee Injury and Osteoarthritis Outcome Score; ADL Activities of Daily Living; QOL Knee-related Quality of Life; Sports/Rec Sports and Recreation; VAS Visual Analogue Scale. KOOS scores range from 0 to 100, 100 being best; Pain VAS Score denoted from 0 to $10 \mathrm{~cm}$, $10 \mathrm{~cm}$ being extreme pain.

Table 2. KOOS subscale scores and pain VAS scores for weeks 0 and 6 in the Siling Labuyo and Control groups

\begin{tabular}{lcccccc} 
KOoS Subscale & \multicolumn{2}{c}{ Siling Labuyo $(\mathbf{N}=\mathbf{2 0})$} & & \multicolumn{2}{c}{ Control Group (N=27) } & Difference Between \\
\cline { 2 - 3 } \cline { 5 - 6 } Groups (p values)
\end{tabular}

Data reported as Mean \pm SE $(95 \% \mathrm{Cl})$.

ADL Activities of Daily Living (similar to WOMAC Function); VAS Visual Analogue Scale.

Pain VAS Scores (in cm). $0 \mathrm{~cm}$ - no pain; $10 \mathrm{~cm}$ - extreme pain.

According to the KOOS Scoring, August 2012, a score of 100 indicates no problem while 0 indicates severe problem.

${ }^{*} P<0.05$ from baseline to week 6 when ANOVA of repeated measures was performed within group.

significant $(\mathrm{p}>0.05)$. Greatest improvement was reported by both groups in the KOOS Sport/Rec dimension (149\% improvement from baseline in the active control group; $84 \%$ in the experimental group). Least improvement was reported by the Siling Labuyo liniment group in the KOOS Sym dimension (31\%), while the Diclofenac gel group reported least improvement in the KOOS pain dimension (42\%).
Table 3 shows the $\mathrm{p}$ values computed for the differences from baseline of the mean KOOS and VAS scores reported by the participants at week 3 and at week 6 for both treatment groups. In the Siling Labuyo liniment group, the Sport/Rec and QOL dimensions as well as the VAS already exhibit significant changes at week 3 , and this is sustained to the end of the treatment period. For the Pain, Sym and 
ADL dimensions of the KOOS, statistically significant increases in mean scores from baseline are attained only at the end of week 6 . In the active control group, significant increases of scores at week 3 is seen in the Pain VAS and in all of the KOOS dimensions except in the Sym dimension. At the end of week 6, all the dimensions showed significant improvement from baseline.

\section{Adverse Events}

Itching ( $\mathrm{n}=6)$, burning sensation ( $\mathrm{n}=5)$ and reddening of the skin $(n=7)$ were experienced in both groups. Other adverse events as well as differences in the occurrence of these events between the two groups are summarized on Table 4. Some of the patients experienced 2 to 3 adverse effects (control, $\mathrm{n}=1$; siling labuyo, $\mathrm{n}=3$ ). The following countermeasures were done by patients who experienced these adverse events: none $(n=9)$, skipped the doses $(n=3)$, washed the drug with water $(n=1)$, took paracetamol $(n=1)$ and stretched the affected knee $(n=1)$. All of these adverse events disappeared within a few days and all participants who experienced the events completed the 6-week trial.

Participants who did not complete the study gave the following reasons for withdrawing: (1) could not meet with the researchers on scheduled monitoring days because of family or work demands ( $n=3)$, and (2) no one to bring the participant to the health center $(\mathrm{n}=2)$ (Figure 2).

\section{Perceived efficacy of treatment}

All participants in the Siling Labuyo group find it effective (very effective in $45 \%$ and slightly effective in $55 \%)$. Majority in the control group consider Diclofenac very effective (59\%) but one participant finds it ineffective. Overall, 95\% of participants in the Siling Labuyo group are willing to continue using the treatment compared to $89 \%$ in the Diclofenac group (Table 5).

\section{DISCUSSION}

This study evaluates the safety and efficacy of the community formulation of Capsicum frutescens liniment in the management of knee $\mathrm{OA}$, particularly in decreasing pain and improving functionality. Across the chosen dimensions, at least 30\% improvement in scores from baseline is observed at the end of week 6 in the experimental and at least $40 \%$ in the control group. Studies comparing capsaicin and NSAIDs in reviewed literature reported similar findings. ${ }^{32,33}$ In this study, Diclofenac gel was chosen because of its availability and widespread use in the country compared to other local topical NSAIDs. Capsaicin cream is not yet commercially available locally. It is noted that significant improvement in some KOOS dimensions was observed only by week 6 in the experimental group consistent with reports on plant-based therapies, suggesting that the therapeutic effect of herbal preparations is slow-acting compared to the more immediate relief observed with the use of topical NSAIDs. ${ }^{34,35}$

Side-effects such as erythema, itching and burning sensation were reported in both groups. These events however were transient, mild and tended to resolve within a few days. None of the participants who experienced those events withdrew from the study. These findings are also consistent with previous studies on topical capsaicin where burning sensation and erythema were the most common

Table 3. P Values from Anova of Repeated Measures Results for Within Group Comparisons

\begin{tabular}{|c|c|c|c|c|c|c|c|c|c|c|c|c|}
\hline \multirow{3}{*}{ Week } & \multicolumn{6}{|c|}{ Siling Labuyo $(\mathrm{N}=20)$} & \multicolumn{6}{|c|}{ Control Group ( $\mathrm{N}=27$ ) } \\
\hline & \multicolumn{5}{|c|}{ KOOS } & \multirow{2}{*}{ VAS } & \multicolumn{5}{|c|}{ KOOS } & \multirow{2}{*}{ VAS } \\
\hline & Pain & Sym & ADL & Sport/Rec & QOL & & Pain & Sym & ADL & Sport/Rec & QOL & \\
\hline 0 & - & - & - & - & - & - & - & - & - & - & - & - \\
\hline 3 & 0.850 & 0.140 & 0.250 & $0.000^{*}$ & $0.030^{*}$ & $0.030^{*}$ & $0.040^{*}$ & 0.090 & $0.020^{*}$ & $0.009^{*}$ & $0.003^{*}$ & $0.000^{*}$ \\
\hline 6 & $0.003^{*}$ & $0.020^{*}$ & $0.002 *$ & $0.015^{*}$ & $0.001^{*}$ & $0.003^{*}$ & $0.000^{*}$ & $0.000^{*}$ & $0.000^{*}$ & $0.008^{*}$ & $0.001^{*}$ & $0.000^{*}$ \\
\hline
\end{tabular}

*significant difference with $p<0.05$.

Sym-Symptoms; ADL-Activities of Daily Living (similar to WOMAC Function); Sport/Rec-Sports and Recreation; QOL-knee-related Quality of Life; VAS-Visual Analogue Scale.

Table 4. Adverse Events Experienced upon Application of the Siling Labuyo Liniment and Diclofenac Gel

\begin{tabular}{lcc} 
Adverse Effects & $\begin{array}{c}\text { Control Group } \\
(\mathbf{n = 2 7 )}\end{array}$ & $\begin{array}{c}\text { Siling Labuyo Group } \\
(\mathbf{n}=20)\end{array}$ \\
\hline Itching & $2(7.4 \%)$ & $4(20 \%)$ \\
Burning sensation & $2(7.4 \%)$ & $3(15 \%)$ \\
Urticaria & $0(0 \%)$ & $2(10 \%)$ \\
Reddening of skin & $4(14.8 \%)$ & $3(15 \%)$ \\
Papules & $1(3.7 \%)$ & $0(0 \%)$ \\
Others* & $1(3.7 \%)$ & $0(0 \%)$ \\
\hline
\end{tabular}

Reported as frequency (\%) of localized adverse effects;

*Others: 1 reported Pain as adverse effect.
Table 5. Perceived Efficacy of Drug

\begin{tabular}{lcc} 
& $\begin{array}{c}\text { Control Group } \\
(\mathbf{n}=\mathbf{2 7})\end{array}$ & $\begin{array}{c}\text { Siling Labuyo Group } \\
(\mathbf{n}=\mathbf{2 0})\end{array}$ \\
\hline Efficacy & & \\
$\quad$ Very Effective & $16(59 \%)$ & $9(45 \%)$ \\
Slightly Effective & $10(37 \%)$ & $11(55 \%)$ \\
$\quad$ Not Effective & $1(3.7 \%)$ & $0(0 \%)$ \\
\hline Agreeable to probable & $24(89 \%)$ & $19(95 \%)$ \\
use in the future & & \\
\hline
\end{tabular}

Reported here as frequency ( $\mathrm{n} \%)$. 
adverse effects reported. ${ }^{18-20,36}$ With continuous use of capsaicin, these side effects were reported to diminish and were attributed to continuous desensitization and neural depletion of substance P. ${ }^{16,35}$

The results of the present study suggest that the community preparation of the Siling Labuyo liniment is comparable to the commercially prepared capsaicin creams studied in reviewed literature. The modest improvement in pain and functionality reported with the use of the capsaicin cream in literature is similar to the improvement seen with the use of the Siling Labuyo liniment in this study. Further, this study shows that the improvement noted with the use of the Siling Labuyo liniment is comparable to that of Diclofenac gel. It is also interesting to note that a higher percentage of participants in the experimental group is willing to continue using the Siling Labuyo liniment after the trial period.

Though the positive results seen in the present study support the use of the community preparation of the Siling Labuyo liniment in managing knee OA at least for selected groups, the study is at best a preliminary trial. The sample size was small; consequently, the results were not statistically conclusive. A larger scale study should be considered in a setting like a busy osteoarthritis clinic. A major difficulty the research team encountered in the recruitment process was the inability of many potential participants to have an $\mathrm{x}$-ray taken of their affected knees because of the distance from their home to medical facilities equipped with an $\mathrm{x}$-ray machine and the cost of the test. Long term studies should also be considered since there have been reports of long lasting benefits with the use of the topical capsaicin with continuous, long term use. ${ }^{16,35}$

\section{CONCLUSION}

The use of the community preparation of the Siling Labuyo liniment during the 6-week community-based clinical trial resulted in modest reductions in pain and symptoms of knee $\mathrm{OA}$ and increased functionality, comparable to the results seen with the use of Diclofenac gel. The Siling Labuyo liniment is also well-tolerated and acceptable for many of the participants for longer term use. The study provided preliminary evidence supporting the promotion of the use of community preparation of the Siling Labuyo liniment in knee osteoarthritis especially in areas where commercial preparations of OA drugs are either geographically or financially inaccessible. Even a modest decrease in pain from knee osteoarthritis and increase in functionality will contribute to a better quality of life for people in these areas.

\section{Acknowledgments}

The study was a project of the Institute of Pharmaceutical Sciences, National Institutes of Health, University of the Philippines Manila. The support and assistance of the Municipal Health Officers, Rural Health Unit staff, and Barangay Health Workers of the municipalities of Alfonso, Mendez and Amadeo were vital in the implementation of this study. The help provided by the students, Family and Community Medicine residents and faculty of the University of the Philippines Manila Community Health and Development Program (UP CHDP) was likewise invaluable. Guidance on statistical analysis was provided by Mr. Bienvenido Cabarro from the College of Public Health, UP Manila.

\section{Statement of Authorship}

All authors approved the final version submitted.

\section{Author Disclosure}

All authors declared no conflict of interest.

\section{Funding Source}

This paper was funded by the Philippine Institute of Traditional and Alternative Healthcare (PITAHC) of the Department of Health.

\section{REFERENCES}

1. Felson DT. The epidemiology of knee osteoarthritis: results from the Framingham osteoarthritis study. Semin Arthritis Rheum. 1990 Dec;20(3 Supp1):42-50.

2. Fransen M, Bridgett L, March L, Hoy D, Penserga E, Brooks P. The epidemiology of osteoarthritis in Asia. Int J Rheum Dis. 2011 May; 14(2):113-21.

3. Jordan KM, Arden NK, Doherty M, Bannwarth B, Bijlsma JW, Dieppe P, et al. EULAR Recommendations 2003: An evidence based approach to the management of knee osteoarthritis: Report of a Task Force of the Standing Committee for International Clinical Studies Including Therapeutic Trials (ESCISIT). Ann Rheum Dis. 2003 Dec; 62(12):1145-55.

4. Fraenkel L, Bogardus ST Jr, Concato J, Wittink DR. Treatment options in knee osteoarthritis: The patient's perspective. Arch Intern Med. 2004 Jun; 164(12):1299-304.

5. Posnett J, Dixit S, Oppenheimer B, Kili S, Mehin N. Patient preference and willingness to pay for knee osteoarthritis treatments. Patient Prefer Adherence. 2015 Jun; 9:733-44.

6. Racaza GZ, Salido EO, Penserga EG. Clinical profile of Filipino patients with osteoarthritis seen at two arthritis clinics. Int J Rheum Dis. 2012 Aug; 15(4):399-406.

7. Rafanan BS Jr, Valdecañas BF, Lim BP, et al. Consensus recommendations for managing osteoarthritic pain with topical NSAIDs in Asia Pacific. Pain Manag. 2018 Mar; 8(2):115-28.

8. Zhang W, Doherty M, Leeb BF, Alekseeva L, Arden NK, Bijlsma JW, et al. EULAR evidence based recommendations for the management of hand osteoarthritis: Report of a Task Force of the EULAR Standing Committee for International Clinical Studies Including Therapeutics (ESCISIT). Ann Rheum Dis. 2007 Mar; 66(3):377-88.

9. Makris UE, Kohler MJ, Fraenkel L. Adverse effects of topical nonsteroidal antiinflammatory drugs in older adults with osteoarthritis: a systematic literature review. J Rheumatol. 2010 Jun; 37(6):1236-43.

10. Endo Pharmaceuticals, Voltaren ${ }^{\circledR}$ gel (Diclofenac sodium topical gel) label warning for cardiovascular and gastrointestinal risk [Online]. 2009 [cited 2018 March.] Available from: http://www.voltarengel. com/ common/pdf/Voltaren-PI-10-19.pdf.

11. McCleane G. The analgesic efficacy of topical capsaicin is enhanced by glyceryl trinitrate in painful osteoarthritis: A randomized, double blind, placebo controlled study. Eur J Pain. 2000; 4(4):355-60. 
12. Schnitzer TJ, Pelletier JP, Haselwood DM, Ellison WT, Ervin $\mathrm{JE}$, Gordon RD, et al. Civamide cream $0.075 \%$ in patients with osteoarthritis of the knee: A 12 -week randomized controlled clinical trial with a longterm extension.J Rheumatol. 2012 Mar; 39(3):610-20.

13. Murray, MT. Capsicum frutescens (Cayenne Pepper). In: Pizzorno JE, Murray MT, eds. Textbook of Natural Medicine. St. Louis, Missouri: Churchill Livingstone; 2013. pp. 633-7.

14. Co LL. Siling Labuyo. In: LL. Co. Common Medicinal Plants of the Cordillera Region. Baguio City, Philippines: Community Health, Education, Services and Training in the Cordillera Region (CHESTCORE); 1989. pp. 236-8.

15. Quisumbing E. Capsicum frutescens Linn. In: Medicinal Plants of the Philippines. Quezon City: Katha Publishing Co., Inc; 1978. pp. 836-8.

16. Fattori V, Hohmann MS, Rossaneis AC, Pinho-Ribeiro FA, Verri WA. Capsaicin: current understanding of its mechanisms and therapy of pain and other pre-clinical and clinical uses. Molecules. 2016 Jun; 21(7):844.

17. Walpole CSJ, Wrigglesworth R, Bevan S, Campbell EA, Dray A, James IF, et al. Analogs of capsaicin with agonist activity as novel analgesic agents; structure-activity studies. 1. The aromatic "A-region". J Med Chem. 1993 Aug; 36(16):2362-72.

18. Winter J, Bevan S, Campbell EA. Capsaicin and pain mechanisms. Br J Anaesth. 1995 Aug; 75(2):157-68.

19. Anand P, Bley K. Topical capsaicin for pain management: therapeutic potential and mechanisms of action of the new high-concentration capsaicin 8\% patch. Br J Anaesth. 2011 Oct; 107(4):490-502.

20. Nolano M, Simone DA, Wendelschafer-Crabb G, Johnson T, Hazen E, Kennedy WR. Topical capsaicin in humans: parallel loss of epidermal nerve fibers and pain sensation. Pain. 1999 May; 81(1-2):135-45.

21. Altman RD, Aven A, Holmburg CE, Pfeifer LM, Sack M, Young GT. Capsaicin cream $0.025 \%$ as monotherapy for osteoarthritis: A doubleblind study. Semin Arthritis Rheum. 1994 Jun; 23(6):25-33.

22. Kosuwon W, Sirichatiwapee W, Wisanuyotin T, Jeeravipoolvarn P, Laupattarakasem W. Efficacy of symptomatic control of knee osteoarthritis with $0.0125 \%$ of capsaicin versus placebo. J Med Assoc Thai. 2010 Oct; 93(10):1188-95.

23. Simone DA, Ochoa J. Early and late effects of prolonged topical capsaicin on cutaneous sensibility and neurogenic vasodilatation in humans. Pain. 1991 Dec; 47(3):285-94.

24. Chopra A, Saluja M, Tillu G, Venugopalan A, Sarmukaddam $\mathrm{S}$, Raut AK, et al. A randomized controlled exploratory evaluation of standardized ayurvedic formulations in symptomatic osteoarthritis knees: A government of India NMITLI project. Evid Based Complement Alternat Med. 2011; 2011:724291.
25. Panahi Y, Alishiri GH, Bayat N, Hosseini SM, Sahebkar A. Efficacy of Elaeagnus angustifolia extract in the treatment of knee osteoarthritis: A randomized controlled trial. EXCLI J. 2016 Mar; 15:203-10.

26. Roos EM, Lohmander LS. The Knee injury and Osteoarthritis Outcome Score (KOOS): From joint injury to osteoarthritis. Health Qual Life Outcomes. Osteoarthritis and Cartilage. 2003 Nov; 1:64.

27. Collins NJ, Prinsen CA, Christensen R, Bartels EM, Terwee CB, Roos EM. Knee Injury and Osteoarthritis Outcome Score (KOOS): systematic review and meta-analysis of measurement properties. Osteoarthritis Cartilage. 2016 Aug; 24(8):1317-29.

28. Villanueva-Misa A, Penserga E. Cross-cultural adaptation and validation of the Filipino translation of the Knee Injury and Osteoarthritis Outcome Score (KOOS) in Filipinos with knee osteoarthritis at the University of the Philippines-Philippine General Hospital (UP-PGH). http://www.koos.nu/koosfilipino.pdf.

29. Crichton N. Information point: Visual Analogue Scale (VAS). J Clin Nurs. 2001; 10:697-706.

30. Kersten P, Küçükdeveci AA, Tennant A. The use of the visual analogue scale (VAS) in rehabilitation outcomes. J Rehabil Med. 2012 Jun; 44(7):609-10.

31. Knuesel O, Weber M, Suter A. Arnica Montana gel in osteoarthritis of the knee: An open, multicenter clinical trial. Adv Ther. 2002 SepOct; 19(5):209-18.

32. Mason L, Moore RA, Derry S, Edwards JE, McQuay HJ. Systematic review of topical capsaicin for the treatment of chronic pain. BMJ. 2004 Apr; 328(7446):991.

33. Meng $Z$, Huang R. Topical treatment of degenerative knee osteoarthritis. Am J Med Sci. 2018 Jan; 355(1):6-12.

34. Gemmell HA, Jacobson BH, Hayes BM. Effect of a topical herbal cream on osteoarthritis of the hand and knee: a pilot study. J Manipulative Physiol Ther. 2003 Jun; 26(5):e15.

35. McKay L, Gemmell H, Jacobson B, Hayes B. Effect of a topical herbal cream on the pain and stiffness of osteoarthritis: A randomized double-blind, placebo-controlled clinical trial.J Clin Rheumatol. 2003 Jun; 9(3):164-9.

36. Guedes V, Castro JP, Brito I. Topical capsaicin for pain in osteoarthritis: A literature review. Rheumatol Clin. 2018 Jan-Feb; 14(1):40-5. 